\title{
Retrospective Antibiotic Prescription Pattern in Public Hospitals in Nasarawa State, Nigeria
}

\author{
Yakubu Boyi Ngwai, Istifanus Haruna Nkene, Rejoice Helma Abimiku, Elisha Yusuf Envuladu
}

\begin{abstract}
Antibiotics are the most frequently used group of drugs in healthcare delivery. Their usage pattern varies between countries and healthcare facilities. Hence, the assessment of their usage pattern in healthcare facilities is pivotal to the successful management of infectious diseases. A descriptive retrospective cross-sectional study on antibiotic prescription pattern in public hospitals in Nasarawa State, Nigeria was carried out. A total of 2800 case sheets of patients which accessed public hospitals during the period of 10 years $(2008-2018)$ were randomly sampled and reviewed. The socio-demographic data of the patients in the case sheets were also collected. Antibiotic use by the patients and the use in relation to their socio-demographic factors were determined using descriptive statistics. The overall percentage antibiotic use in Nasarawa State was $45.8 \%$. Nasarawa West $(64.4 \%)$ had highest use; while Nasarawa South $(52.7 \%)$ was the lowest. More females $(63.4 \%)$ than males $(61.3 \%)$ used antibiotics. Highest use was observed at age 0-10 yr (67.0\%); and lowest at >50 yr

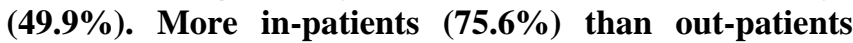
$(52.7 \%)$ used antibiotics. Ciprofloxacin $(28.0 \%)$ was the most commonly used antibiotic; and streptomycin $(0.4 \%)$ was the least used. More oral antibiotics $(63.4 \%)$ than injectables $(36.4 \%)$ were used. the antibiotic use in typhoid fever $(39.8 \%)$ was highest; and lowest in eye infections $(0.5 \%)$. The percentage used of antibiotics under the period reviewed was high and antibiotics namely; ciprofloxacin, gentamicin and metronidazole were most common antibiotic prescribed.
\end{abstract}

Index Terms-Antibiotic, healthcare delivery, Prescription pattern, public hospitals.

\section{INTRODUCTION}

Drugs are important to healthcare, being the most frequently used intervention and one of the most cost-effective components (WHO, 2004). Antibiotics, medications that can destroy or inhibit the growth of bacteria by either selectively killing or inhibiting the development of disease-causing bacteria (ECDPC, 2008; Leekha et al., 2011), are currently the most frequently prescribed drugs in hospitals worldwide

Yakubu Boyi Ngwai, Department of Microbiology, Nasarawa State University, Keffi

Istifanus Haruna Nkene, Department of Microbiology, Nasarawa State University, Keffi, Nigeria

Rejoice Helma Abimiku, Research Department, Plateau State Human Virology Research Centre (PLASVIREC), Jos, Nigeria

Elisha Yusuf Envuladu, Pharmacy Department, Federal Medical Centre, Keffi, Nigeria
(Yimenu et al., 2019). Antibiotics play critical role in the management of infectious diseases especially in developing countries where infections are still a major challenge (Yimenu et al., 2019). Their consumption has increased worldwide with most of this occurring in low- and middle-income countries (Admassie et al., 2013).

The antibiotic prescription pattern varies significantly between countries and healthcare facilities (DACAE, 2009; Ntšekhe et al., 2011; Chem et al., 2018; Yimenu et al., 2019). In resource-scarce setting where routine empirical antibiotic use is widespread, prescription pattern also vary widely (Eshiet et al., 2015). For instance, some studies reported that fluoroquinolones, penicillins and cephalosporins are the most prescribed classes of antibiotics (Eshiet et al., 2015) while other studies reported high level use of beta-lactams (Mollahaliloglu et al., 2012; Chem et al., 2018).

Several studies on antibiotic use in Nigeria and abroad have been reported (Babalola et al., 2011; Abdu-Aguye et al., 2016; Atif et al., 2016; Rajallingam et al., 2016; Aboh et al., 2018; Chem et al., 2018; Cole \& Routledge, 2018; Sumaila \& Tabong, 2018; Umar et al., 2018; Amaha et al., 2019; Paul \& Abdulmalik, 2019; Yimenu et al., 2019). However studies on antibiotic use in health care centres in Nasarawa State, Nigeria are lacking, hence this study investigates antibiotics used in both secondary and tertiary health care centres in Nasarawa State, Nigeria. Appropriate antibiotic prescription is the first step to guarantee optimum antibiotic use; and has the potential impact to reduce antimicrobial resistance (AMR) generated by overuse of antimicrobials.

\section{II. . EXPERIMENTAL}

\section{A. Study Area}

The study was conducted in tertiary and secondary healthcare centres in Nasarawa State, Nigeria. The healthcare centres include all general hospitals, specialist hospitals and Federal Medical Centre, Keffi.

\section{B. Study Design and Outcome Variable}

It was a prospective, descriptive and observational study, designed according to the objectives of the study. The outcome indicators are related to antimicrobial use; and hospital prescribing indicators.

\section{Study inclusion/exclusion criteria}

All patients, from both genders and all age groups, tertiary and secondary health care centres in Nasarawa State, Nigeria, 
during the study period from January 2008 to December 2018, were included in our study.

\section{Ethical Approval}

Ethical clearance for the study was obtained from the Ethics and Scientific Review Committee at the Nasarawa State Hospital Management Board, Lafia. Before the approval was given, the Research Protocol and Informed Consent were submitted and defended before the Committee.

\section{E. Sampling and Data Collection}

The WHO's "How to investigate drug use in health facilities" recommends at least 600 encounters to be included in a cross-sectional survey involving a drug use survey (WHO, 1993). However, we collected 2800 case sheets of patients for the period of 10 years from January 2008 to December 2018. The standard forms provided by WHO were used for data collection. The guidelines and methods were followed to ensure the reliability of all collected data (WHO, 2012).

\section{RESULTS AND DISCUSSION}

\section{A. Percentage Antibiotic Use}

The percentage antibiotic use in Nasarawa State during the period of 10 years (2008-2018) and zone-related use are shown in Figure 1. The percentage antibiotic use in all the hospitals was $45.8 \%$; the highest in Nasarawa West (64.4\%) and lowest in Nasarawa South $(52.7 \%)$.

\section{B. Hospital-related Antibiotic Use}

Hospital-related antibiotic use was highest (87\%) in General Hospital Awe and lowest (37\%) in Dalhatu Araf Specialist Hospital Lafia as shown in Figure 2. Antibiotic use was over $50 \%$ in most $(71.4 \%)$ of the hospitals and less than $50 \%$ in $28.6 \%$ of the hospitals.

\section{Gender-related Antibiotic Use}

Gender-related use indicated higher use in females (63.4\%) than males $(61.3 \%)$ as shown in Figure 3. Antibiotic use was higher in females in $50 \%$ of the hospitals; but higher in males in $42.9 \%$ of the hospitals; and of equal proportion in $0.1 \%$ of the hospitals.

\section{Age-related Antibiotic Use}

Age-related use in all the hospitals was highest at 0-10 yr $(67.0 \%)$ and lowest at $>50 \mathrm{yr}(49.9 \%)$ as shown in Figure 4. The percentage antibiotic use was highest (97.8\%) at 11-20 yr in General Hospital Awe and the lowest (22.2\%) at 31-40 yr in Federal Medical Centre, Keffi.

\section{E. Patient's Category-related Antibiotic Use}

Antibiotic use was higher amongst in-patients $(75.6 \%)$ than out-patients $(52.7 \%)$ as shown in Figure 5. The usage amongst in-patients was highest in General Hospital Obi (98.3\%) and lowest in General Hospital Akwanga (56.8\%) and General Hospital Nasarawa Eggon (56.8\%). Out-patients' usage was highest in General Hospital Wamba (95.0\%) and lowest in General Hospital Keana (26.0\%).

\section{F. Route-related Antibiotic Use}

More oral antibiotics (63.4\%) than injectables (36.4\%) were used as shown in Figure 6. The highest oral usage was in Dalhatu Araf Specialist Hospital Lafia (83.3\%) and the lowest was in Federal Medical Centre, Keffi (37.2\%). For the injectable use, the highest was in Federal Medical Centre, Keffi $(62.8 \%)$ and the lowest was in General Hospital Obi (21.2\%).

\section{G. Diagnosis-related Antibiotic Use}

The order of percentage antibiotic use in diseases was as follows: Typhoid fever $(39.8 \%)>$ urinary tract infections $(22.7 \%)=$ gastroenteritis $(22.7 \%)>$ upper respiratory tract infections $(7.1 \%)>$ soft tissue infections $(2.7 \%)>$ bloodstream infections $(2.4 \%)>$ vaginitis $(2.1 \%)>$ ear infections $(0.9 \%)>$ eye infections $(0.5 \%)$ as shown in Figure 7. Hospital-based antibiotic use for disease conditions shows highest use for typhoid fever in $71.4 \%$ (10/14) of the healthcare centers, except: General Hospital Nasarawa Eggon, Dalhatu Araf Specialist Hospital Lafia, Federal Medical Center Keffi and General Hospital Toto; and predominant use for urinary tract infections in only $21.4 \%$ (3/14) of the healthcare centers, namely: Dalhatu Araf Specialist Hospital Lafia, Federal Medical Center Keffi and General Hospital Toto.

\section{H. Antibiotic Class-related Use}

The most commonly used antibiotic in the hospitals was ciprofloxacin $(28.0 \%)$, and the least used was streptomycin $(0.4 \%)$ as shown in Figure 8.

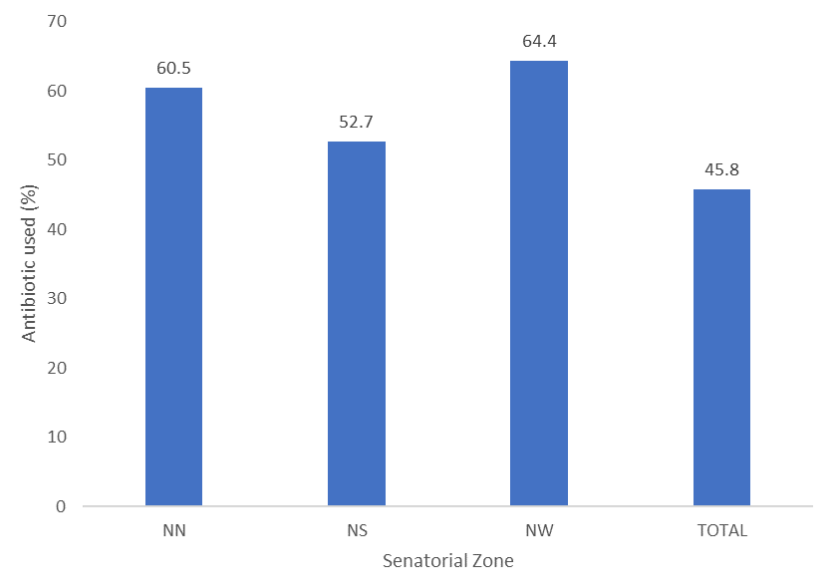

Figure 1: Percentage antibiotic use in relation to senatorial zone of the public hospitals where patients accessed healthcare in Nasarawa State, Nigeria during the period 2008-2018 ( $N N=$ Nasarawa North; $N S=$ Nasarawa South; NW= Nasarawa West). 


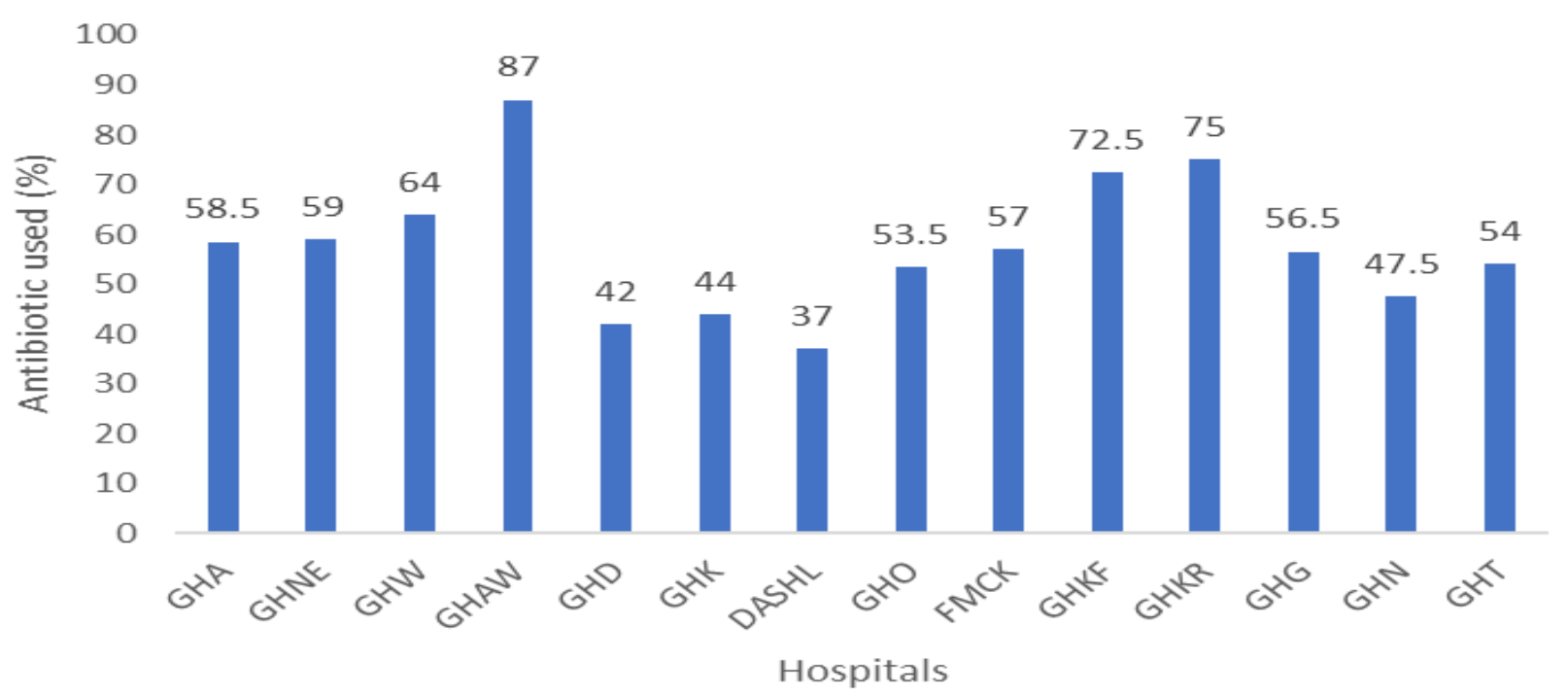

Figure 2: Percentage antibiotic use in relation to the public hospitals where patients accessed healthcare in Nasarawa State, Nigeria during the period 2008-2018 (GHA= General Hospital, Akwanga; GHNE= General Hospital, Nasarawa Eggon; GHW= General Hospital, Wamba; GHAW= General Hospital, Awe; GHD= General Hospital, Doma; GHK= General Hospital, Keana; DASHL=Dalhatu Araf Specialist Hospital, Lafia; GHO= General Hospital, Obi; FMCK= Federal Medical Centre, Keffi; GHKF= General Hospital, Keffi; GHKR= General Hospital, Karu; GHG= General Hospital, Garaku; GHN= General Hospital, Nasarawa; GHT= General Hospital, Toto).

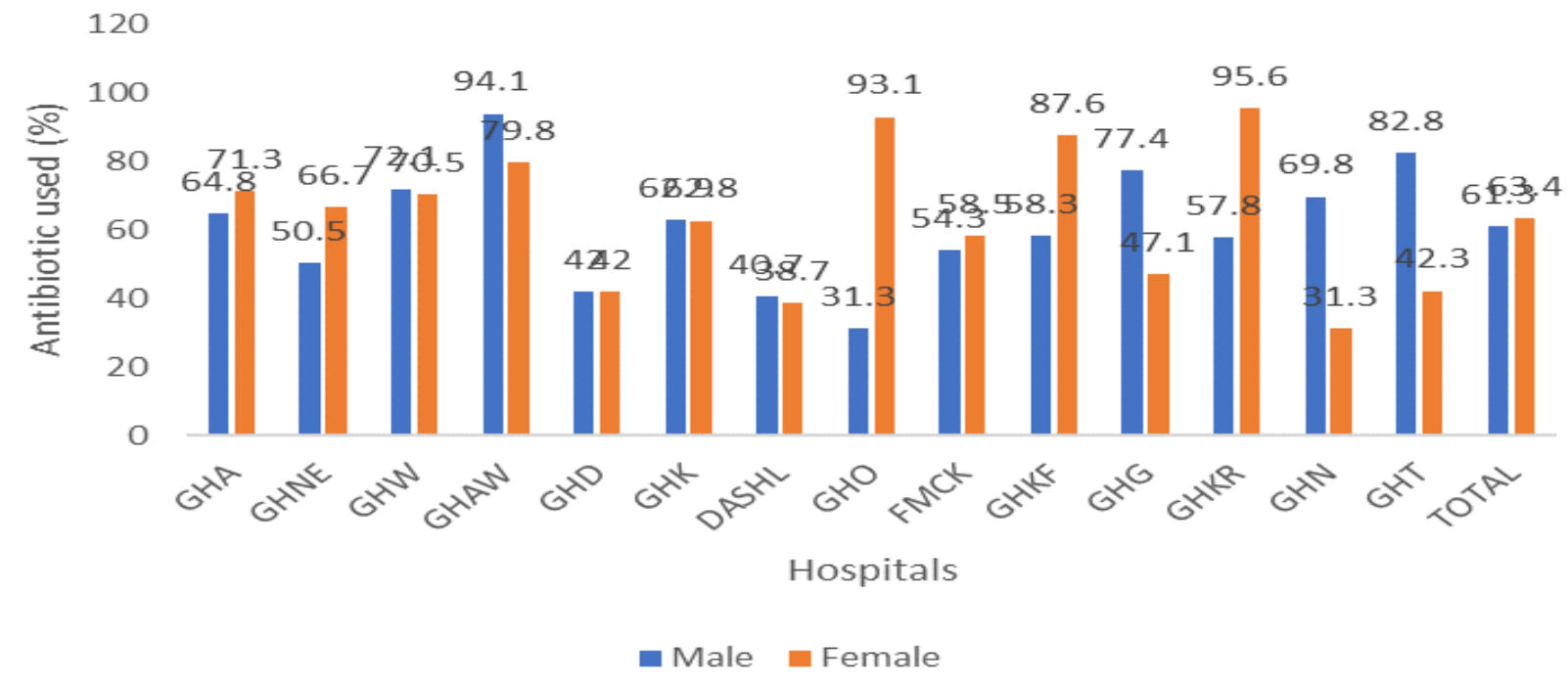

Figure 3: Percentage antibiotic use in relation to the gender of patients who accessed public hospitals in Nasarawa State, Nigeria during the period 2008-2018.(GHA= General Hospital, Akwanga; GHNE= General Hospital, Nasarawa Eggon; GHW= General Hospital, Wamba; GHAW= General Hospital, Awe; GHD= General Hospital, Doma; GHK= General Hospital, Keana; DASHL= Dalhatu Araf Specialist Hospital, Lafia; GHO= General Hospital, Obi; FMCK= Federal Medical Centre, Keffi; GHKF= General Hospital, Keffi; GHKR= General Hospital, Karu; GHG= General Hospital, Garaku; GHN= General Hospital, Nasarawa; GHT= General Hospital, Toto). 


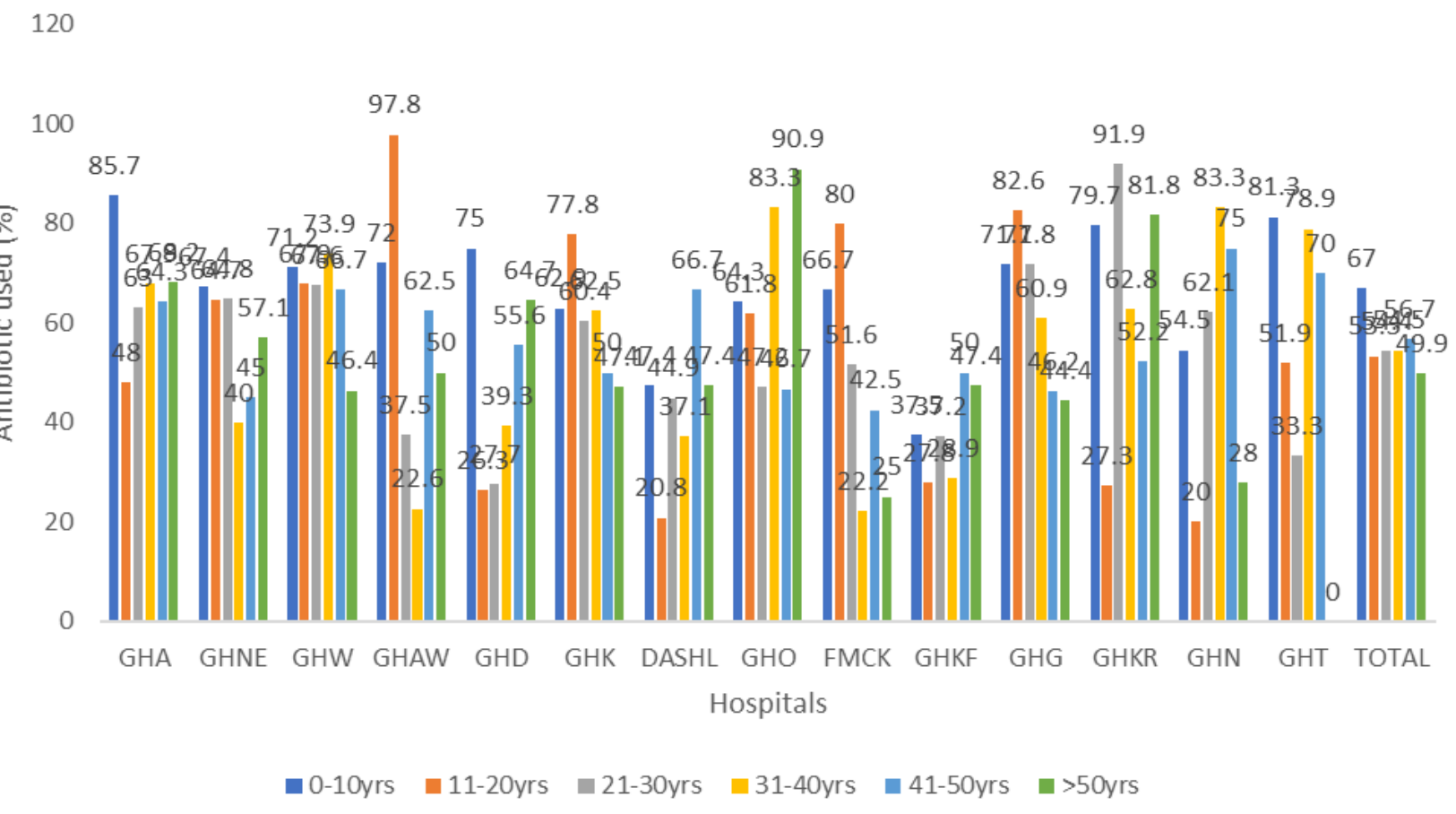

Figure 4: Percentage antibiotic use in relation to the age of patients who accessed public hospitals in Nasarawa State, Nigeria during the period 2008-2018 (GHA= General Hospital, Akwanga; GHNE= General Hospital, Nasarawa Eggon; GHW= General Hospital, Wamba; GHAW= General Hospital, Awe; GHD= General Hospital, Doma; GHK= General Hospital, Keana; DASHL= Dalhatu Araf Specialist Hospital, Lafia; GHO= General Hospital, Obi; FMCK= Federal Medical Centre, Keffi; GHKF= General Hospital, Keffi; GHKR= General Hospital, Karu; GHG= General Hospital, Garaku; GHN= General Hospital, Nasarawa; GHT= General Hospital, Toto).

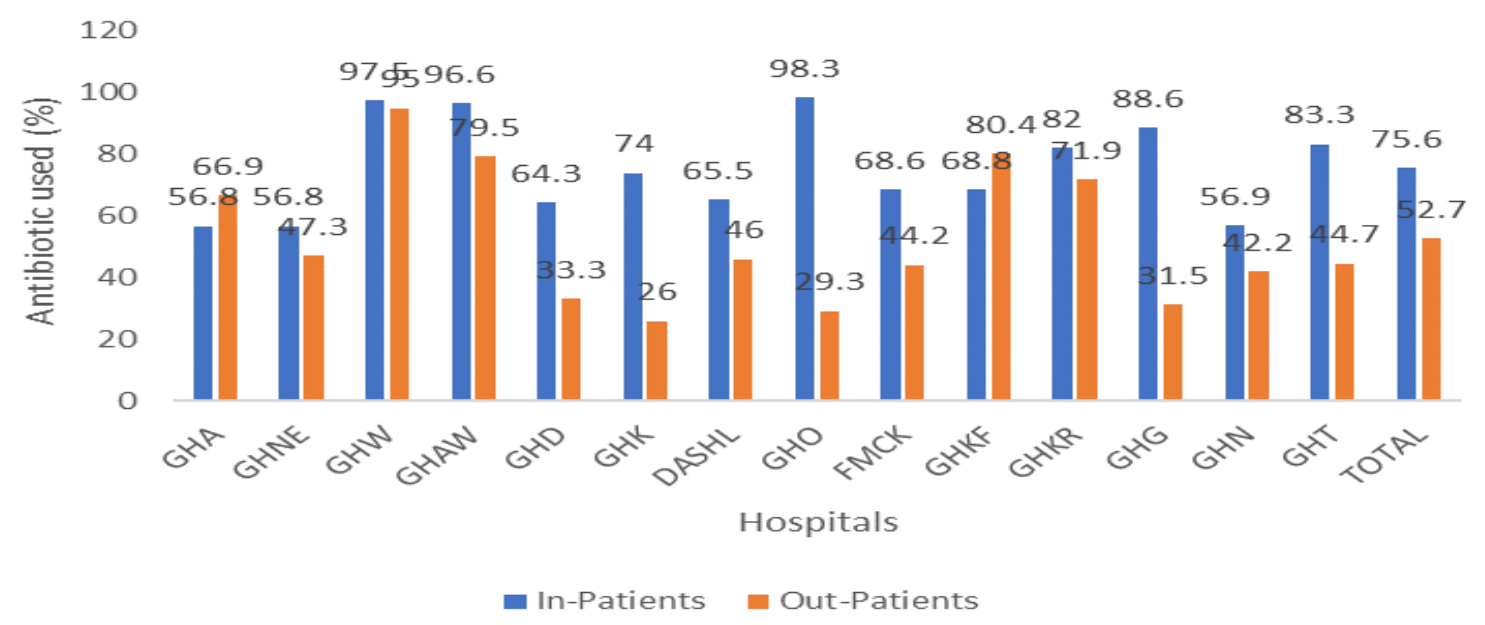

Figure 5: Percentage antibiotic use in relation to the category of patients who accessed public hospitals in Nasarawa State, Nigeria during the period 2008-2018 (GHA= General Hospital, Akwanga; GHNE= General Hospital, Nasarawa Eggon; GHW= General Hospital, Wamba; GHAW= General Hospital, Awe; GHD= General Hospital, Doma; GHK= General Hospital, Keana; DASHL= Dalhatu Araf Specialist Hospital, Lafia; GHO= General Hospital, Obi; FMCK= Federal Medical Centre, Keffi; GHKF= General Hospital, Keffi; GHKR= General Hospital, Karu; GHG= General Hospital, Garaku; GHN= General Hospital, Nasarawa; GHT= General Hospital, Toto). 


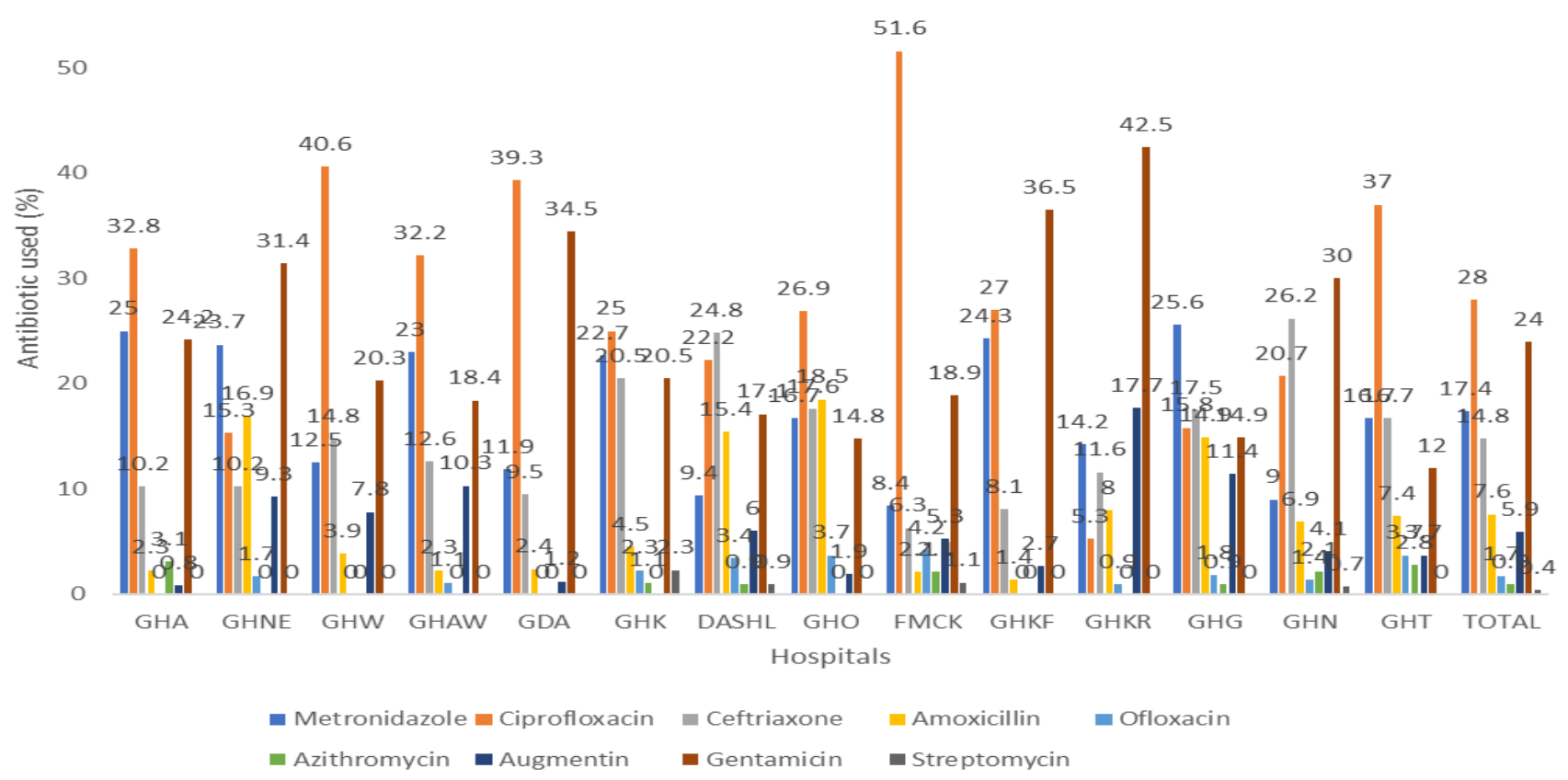

Figure 6: Percentage antibiotic use in relation to the type of antibiotics used by patients who accessed public hospitals in Nasarawa State, Nigeria during the period 2008-2018 (GHA= General Hospital, Akwanga; GHNE= General Hospital, Nasarawa Eggon; GHW= General Hospital, Wamba; GHAW= General Hospital, Awe; GHD= General Hospital, Doma; GHK= General Hospital, Keana; DASHL= Dalhatu Araf Specialist Hospital, Lafia; GHO= General Hospital, Obi; FMCK= Federal Medical Centre, Keffi; GHKF= General Hospital, Keffi; GHKR= General Hospital, Karu; GHG= General Hospital, Garaku; GHN= General Hospital, Nasarawa; GHT= General Hospital, Toto).

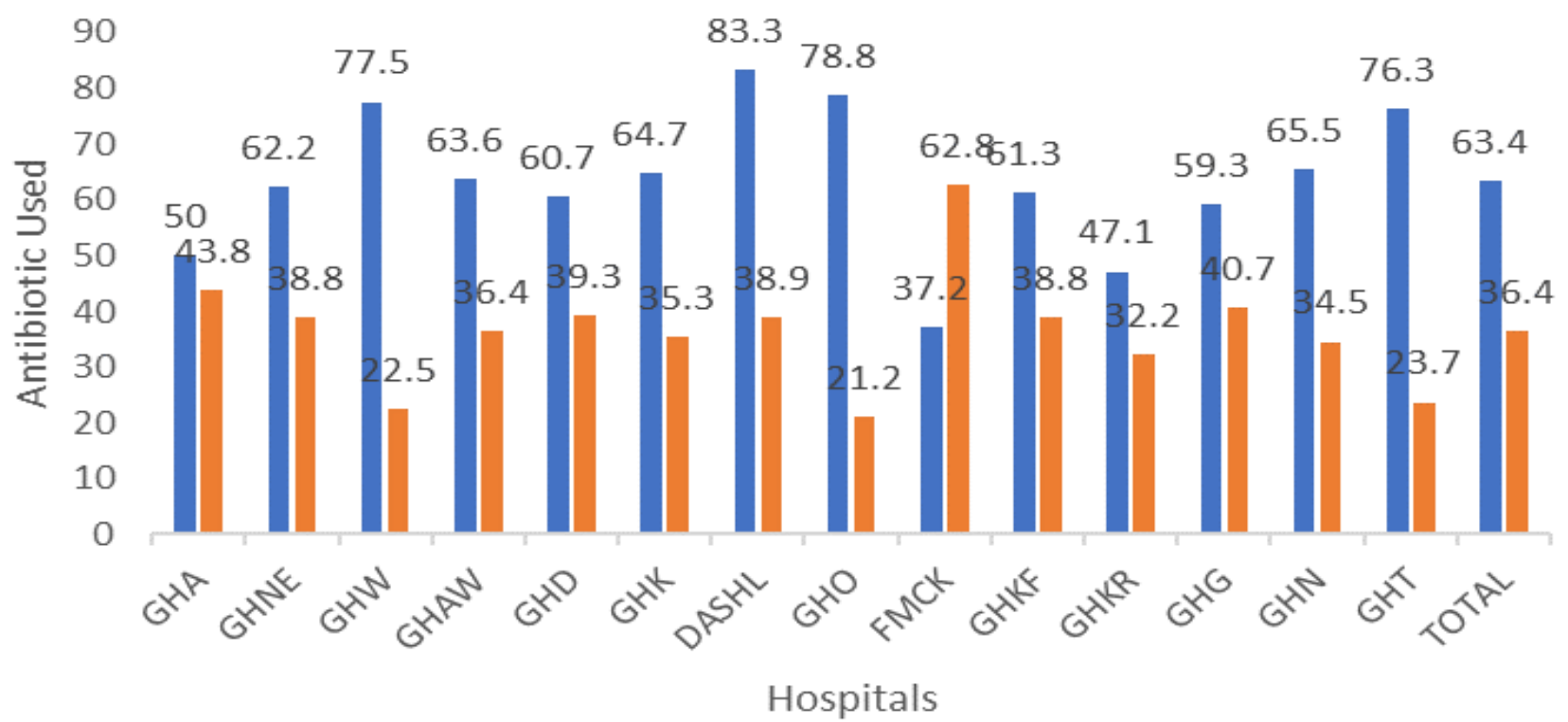

- Oral antibiotics a IV antibiotics

Figure 7: Percentage antibiotic use in relation to route of administration in patients who accessed public hospitals in Nasarawa State, Nigeria during the period 2008-2018 (GHA= General Hospital, Akwanga; GHNE= General Hospital, Nasarawa Eggon; GHW= General Hospital, Wamba; GHAW= General Hospital, Awe; GHD= General Hospital, Doma; GHK= General Hospital, Keana; DASHL= Dalhatu Araf Specialist Hospital, Lafia; GHO= General Hospital, Obi; FMCK= Federal Medical Centre, Keffi; GHKF=General Hospital, Keffi; GHKR= General Hospital, Karu; GHG= General Hospital, Garaku; GHN= General Hospital, Nassarawa; GHT= General Hospital, Toto). 


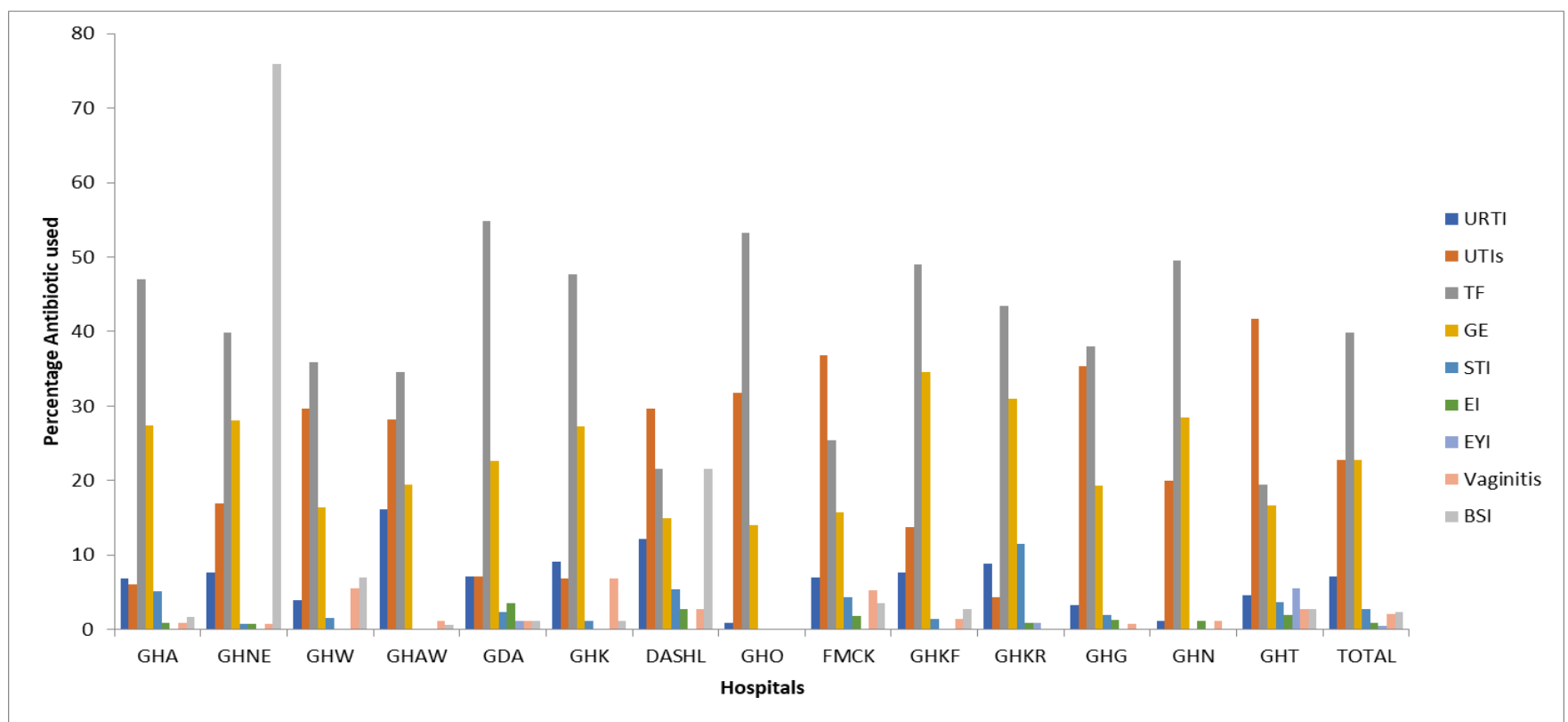

Figure 8: Percentage Antibiotic use in relation to diagnosis of patients who accessed public hospitals in Nasarawa State, Nigeria during the period 2008-2018 (URTI=Upper Respiratory Tract Infection; UTIs=Urinary Tract Infection; TF=Typhoid Fever; GE=Gastroenteritis; SFT=Soft Tissue Infection; EI=Ear Infection; EYI=Eye Infection; BSI=Blood Stream Infection; GHA= General Hospital, Akwanga; GHNE= General Hospital, Nasarawa Eggon; GHW= General Hospital, Wamba; GHAW= General Hospital, Awe; GHD= General Hospital, Doma; GHK= General Hospital, Keana; DASHL= Dalhatu Araf Specialist Hospital, Lafia; GHO= General Hospital, Obi; FMCK= Federal Medical Centre, Keffi; GHKF=General Hospital, Keffi; GHKR= General Hospital, Karu; GHG= General Hospital, Garaku; GHN= General Hospital, Nassarawa; GHT= General Hospital, Toto).

The global consumption of antibiotics has increased, especially in low- and middle-income countries where infectious diseases are still a major challenge, and these drugs are often prescribed inappropriately (Admassie et al., 2013; Atif et al., 2016). Antibiotic prescription pattern varies between countries and healthcare facilities (DACAE, 2009; Ntšekhe et al., 2011; Chem et al., 2018; Yimenu et al., 2019). The overall percentage antibiotic use by patients in public hospitals in Nasarawa State during the period 2008-2018 was $45.8 \%$. This value is higher than the WHO (20.0-26.8\%) standard (Atif et al., 2016a) but similar to the African (45.9\%) standard (Ofori-Asenso et al., 2016). Studies elsewhere have reported $50.4 \%$ in Osun State, Nigeria (Babalola et al., 2011), 69.6\% in Gondar, Ethiopia (Yimenu et al., 2019), 95.0\% in Addis Ababa, Ethiopia (Fikru et al., 2018), 79\% in Eritrea (Amaha et al., 2018) and $83.5 \%$ in Ilorin, Nigeria (Akande et al., 2009), among others. It thus appears that antibiotic use in our study area, as with African countries, is excessive. This is not surprising because in developing countries antibiotics are prescribed for $44 \%$ to $97 \%$ of hospitalized patients often unnecessarily or inappropriately (Hariharan et al., 2009; Ider et al., 2010; Yimenu et al., 2019). Overuse of antibiotics is a common problem in health care, which leads to unnecessary expenditure on drugs, raised risk of adverse reactions, and the development of antimicrobial resistance (Yimenu et al., 2019). Antibiotic resistance is a global public health problem that affects both developing and developed countries (Goossens et al., 2005; WHO, 2015). It is estimated that antibiotic resistance is responsible for more than 2 million infections and 23000 deaths each year in the United States, at a direct cost of $\$ 20$ billion.20 (CDC, 2013).

Our study revealed that antibiotic prescription pattern varies between the hospitals; with the highest $(87 \%)$ in General Hospital Awe and lowest (37\%) in Dalhatu Araf Specialist Hospital Lafia. Awe town in Nasarawa State is a more rural community than Lafia, the State capital of Nasarawa State where Dalhatu Araf Specialist Hospital is located. The higher status of DASHL and its more urban location might have accounted for the higher quality of antibiotic prescription pattern observed there. Our observation confirms the previous reports both in Nigeria and abroad in other antibiotic prescription pattern varies between countries and healthcare facilities (Akande et al., 2009; Babalola et al., 2011; Ntšekhe et al., 2011; Abdu-Aguye et al., 2018; Cole \& Routledge, 2018; Chem et al., 2018; Paul \& Abdulmalik, 2018; Umar et al., 2018; Yimenu et al., 2019).

We found that slightly more females $(63.4 \%)$ than males $(61.3 \%)$ used antibiotics in the public hospitals in Nasarawa State, Nigeria; with variations between the health facilities as expected. Our findings agrees with those of Fikru et al. (2018) from Addis Ababa, Ethiopia, Smith et al. (2018) from England, Anong et al. (2018) from Cameroon and Streit et al. (2015) from Switzerland, who reported that females are more significantly associated with antibiotic prescribing; but contrasted with those of Amaha et al. (2019) in Eritrea, Liazu et al. (2018) in Bangladesh and Gube et al. (2017) in Ethiopia. A previous study has found a significant association 
of antibiotic prescription with patients' gender (Amaha et al., 2019).

Antibiotic use was found in the hospitals to be highest at 0-10 $\mathrm{yr}(67.0 \%)$ and lowest at $>50 \mathrm{yr}(49.9 \%)$. Yimenu et al. (2019) reported the highest antibiotic use in Gondar, Ethiopia by patients at age 15-30 yrs, in contrast with our findings. However, similar studies from Addis Ababa (Fikru et al., 2018) Bangladesh (Liazu et al., 2018), Yemen (Alshakka et al., 2016), Cameroon (Anong et al., 2018) and Asmara, Eritrea (Amaha et al., 2019) found that patients under the age of 15 received the highest proportion of antibiotics when compared with the other patient groups. Amaha et al. (2019) has found significant association of antibiotic prescription with patients' age, with greater likelihood of antibiotic use among patients below 15 years than those older, especially 65 years and above.

The percentage antibiotic use was higher amongst in-patients $(75.6 \%)$ than out-patients $(52.7 \%)$; at the range of $56.8-98.3 \%$ amongst in-patients and 26.0-95.0\% amongst out-patients. Our finding that in-patients received more antibiotics than out-patients is in agreement with a study from Gondar, Ethiopia by Yimenu et al. (2019) which reported percentage used of antibiotics in in-patients than the out-patients.

Our study found that more oral antibiotics (63.4\%) than injectables $(36.4 \%)$ were used in the public hospitals in Nasarawa State, Nigeria; and the highest oral usage was observed in Dalhatu Araf Specialist Hospital Lafia (83.3\%) while the highest injectable use was in Federal Medical Centre, Keffi $(62.8 \%)$. Some studies elsewhere reported lower percentage injectable antibiotic use: $4 \%$ by Yimenu et al. (2019), 7.8\% in Eritrea by Amaha et al., (2019), 11.2\% in Ethiopia (Bilal et al., 2016) and 26\% in Sierra Leone by Cole \& Routledge, 2018); while other studies reported higher values: $38 \%$ by Desalegn (2013) and $67.7 \%$ in Zaria, Nigeria by Umar et al., (2018). The greater use of oral antibiotics observed in our study agrees with Fikru et al. (2018) who reported $94.8 \%$ oral use and $2.8 \%$ injectable use in Addis Ababa, Ethiopia. The observed percentage injectable use is higher than both the WHO (13.4-24.1\%) standard (Atif et al., 2016a) and the African (28.4\%) standard (Ofori-Asenso et al., 2016), suggesting overuse of injections that is not appropriate as unnecessary use of injections increases treatment costs, increases risk of infection with blood borne pathogens if needle stick injuries arise and injections need trained health care professional to administer (WHO, 2011). The Authorities of these hospitals are encouraged to improve on their oral antibiotic prescribing to ensure patients' safety and affordability of drugs.

Diagnosis-related antibiotic use revealed greater use in diseases typhoid fever $(39.8 \%)$, urinary tract infections $(22.7 \%)$ and gastroenteritis $(22.7 \%)$, with lowest use ear infections $(0.9 \%)$ and eye infections $(0.5 \%)$. This finding is at variance with Yimenu et al. (2019) who reported gastrointestinal tract infections (28\%) were the most common diagnosis followed by lower respiratory tract infections (19.4\%).

The study revealed that the most prescribed antibiotics in the hospitals were ciprofloxacin $(28.0 \%)$, gentamicin $(24.0 \%)$ and metronidazole $(17.4 \%)$ and the least used was streptomycin $(0.4 \%)$. This finding contrast with those of Woldu et al. (2013) and Yimenu et al. (2019) who reported that amoxicillin $(28.6 \%)$ was the most prescribed antibiotic, followed by ciprofloxacin (12\%) and metronidazole (11.1\%); Fikru et al. (2018) reported gentamicin (100\%) and ceftriaxone $(98 \%)$ as the most prescribed antibiotics used; Paul and Abdulmalik (2019) reported amoxicillin/clavulanic acid, metronidazole and ciprofloxacin as the most prescribed; Atif et al. (2016b) reported ceftriaxone $(71.8 \%)$ as the most prescribed, followed by cefotaxime $(5.6 \%)$, metronidazole $(4.7 \%)$ and ciprofloxacin $(4.2 \%)$.

\section{CONCLUSION}

The percentage antibiotic used in the study area was high and ciprofloxacin, gentamicin and metronidazole were the most common antibiotic prescribed. The antibiotic use in typhoid fever was highest; and lowest in eye infections.

\section{ACKNOWLEDGMENT}

This research was funded by the "Institution-Based Research grant 2016 merged", awarded to Professor Y.B. Ngwai PhD and Dr. I.H. Nkene PhD by Tertiary Trust Fund (TETFund), Abuja, Nigeria.

\section{REFERENCES}

[1] S. N. Abdu-Aguye, A. Haruna, A. Shehu, and K. S. Labaran. An assessment of antimicrobial prescribing at a tertiary hospital in North western Nigeria. African Journal Pharmacology and Therapy, 2016, 5(4):229-234

[2] E. Admassie, B. Begashaw, W. H. Tesfaye. Assessment of drug use practices and completeness of prescriptions in Gondar university teaching referral hospital. Int J Pharm Sci Res. 2013, 4:265-275.

[3] T. M. Akande, M. Ologe, G. F. Medubi, Antibiotic Prescription Pattern and Cost at University of Ilorin Teaching Hospital, Ilorin, Nigeria. International Journal of Tropical Medicine, 2009, 4(2): 50-54.

[4] O. Akinyandenu, and A. Akinyandenu. Irrational use and non-prescription sale of antibiotics in Nigeria: A need for change. Journal of Scientific Innovative Research, 2014, 3(2):251-257.

[5] M. Alshakka, K. Said, M. Babakri, M. Ansari, A. Aldhubhani, M. A. Hassali, M. I. M. Ibrahim. A study on antibiotics prescribing pattern at outpatient department in four hospitals in Aden-Yemen. J Pharm Pract Community Med. 2016, 2(3):88-93.

[6] N. D. Amaha, Y. H. Berhe, and A. Kaushik. Assessment of inpatient antibiotic use in Halibet National Referral Hospital using WHO indicators: a retrospective study. BMC Research Notes, 2018, 11:904

[7] D. N. Anong, J. F. K. Akoachere. Prescribing patterns and associated factors of antibiotic prescription in primary health care facilities of Kumbo east and Kumbo west health districts, North West Cameroon. PloS one. 2018; 13(3): e0193353.

[8] M. Atif, M. R. Sarwar, M. Azeem M, Umer D, Rauf A. Rasool, M. Ahsan, S. Scahill. Assessment of WHO/INRUD core drug use indicators in two tertiary care hospitals of Bahawalpur, Punjab, Pakistan. J Pharm Policy Pract. 2016, 9(1):27.

[9] C. P. Babalola, S. A. Awoleye, J. O. Akinyemi, O. A. Kotila. Evaluation of prescription pattern in Osun State (Southwest) Nigeria. Journal of Public Health and Epidemiology. 2011, 3(3): 94-98. 
[10] Centers for Disease Control and Prevention. Antibiotic resistance threats in the United States. https://www.cdc.gov/drugresistance/pdf/ar-threats-2013-508.pdfhttp:// apps.who.int/medicinedocs/documents/s23172en/s23172en. Published 2013. Accessed October 21, 2019.

[11] E. D. Chem, D. N. Anong, J. K. T. Akoachere. Prescribing patterns and associated factors of antibiotic prescription in primary health care facilities of Kumbo East and Kumbo West Health Districts, North West Cameroon. PLoS One. 2018; 13: e0193353.

[12] M. Chlabicz, and S. Chlabicz. "Outpatient use of systemicantibioticsinPoland:2004-2008,"EpidemiologicalReview, 2014, 68 (1):435-441.

[13] D. Cui, X. Liu, P. Hawkey, H. Li, Q. Wang, Z. Mao, J. Sun. Use of and microbial resistance to antibiotics in China: A path to reducing antimicrobial resistance. Journal of International Medical Research, 2017, 45(6):1768-1778.

[14] A.A. Desalegn. Assessment of drug use pattern using WHO prescribing indicators at Hawassa University Teaching and Referral Hospital, south Ethiopia: a cross-sectional study. BMC Health Serv Res. 2013, 13:170.

[15] Drug Administration and Control Authority of Ethiopia; Management Sciences for Health, Strengthening Pharmaceutical Systems. Antimicrobials use, resistance and containment baseline survey syntheses of findings. http://apps.who.int/medicinedocs/en/m/abstract/Js18057en/. Published August 2009. Accessed October 7, 2019.

[16] U. I. Eshiet, G. S. Effiong, and A. E. Akwaowoh. The use of antibiotics in a Nigerian tertiary healthcare facility. American Journal of Biomedical Science and Engineering, 2015, 1(3):25-31.

[17] European Centre for Disease Prevention and Control. Factsheet for experts-antimicrobial

resistance.https://www.ecdc.europa.eu/en/antimicrobial-resistance/fac ts/factsheets/experts. Published 2008. Accessed October 7, 2019.

[18] F. Worku, and D. Tewahido. Retrospective Assessment of Antibiotics Prescribing at Public Primary Healthcare Facilities in Addis Ababa, Ethiopia. Interdisciplinary Perspectives on Infectious Diseases, 2018:1-9

[19] H. Goossens, M. Ferech, R. V. Stichele, M. Elseviers. ESAC Project Group. Outpatient antibiotic use in Europe and association with resistance: a cross-national database study. Lancet. 2005;365:579-587.

[20] A. Gube, R. Gonfa, T. Tadesse. Evaluation of antibiotic use in medical Ward of Fitche District hospital, north Showa zone, Oromia region, Ethiopia. Adv Pharmacoepidemiol Drug Saf. 2017;6(217):2167-1052 1000217.

[21] S. Hariharan, G. Pillai, D. Mcintosh, Z. Bhanji, L. Culmer, K. Harper-Mcintosh. Prescribing patterns and utilization of antimicrobial drugs in a tertiary care teaching hospital of a Caribbean developing country. Fundam Clin Pharmacol.2009;23:609-615.

[22] B. E. Ider, A. Clements, J. Adams, M. Whitby, T. Muugolog. Prevalence of hospital-acquired infections and antibiotic use in two tertiary Mongolian hospitals. J Hosp Infect. 2010;75:214-219.

[23] A. O. Isah, D. Ross-Degnan, J. Quick, R. Laing, A. F. B. Mabadeje. The development of standard values for the WHO drug use prescribing indicators, 2019, Published 2004.

[24] D. Jasovsk'y, J. Littmann, A. Zorzet, and O. Cars. Antimicrobial resistance - a threat to the world's sustainable development. Upsala Journal of Medical Sciences, 2016, 121(3):159-164.

[25] S. Kariuki, M. A. Gordon, N. Feasey, and C. M. Parry. Antimicrobial resistance and management of invasive Salmonella disease. Vaccine, 2015, 33(3):C21-C29

[26] A. Kaur, R. Bhagat, N. Kaur, N. Shafiq, V. Gautam, S. Malhotra, V. Suri, A. Bhalla. A study of antibiotic prescription pattern in patients referred to tertiary care centre in Northern India. TherapAdv Infect Dis. 2018;5(4):63-68.

[27] A. Kotwani, and K. Holloway. Access to antibiotics in New Delhi, India: implications for antibiotic policy," Journal of Pharmaceutical Policy and Practice, 2013, 6(1), Article ID 6.
[28] J. Laizu, R. Parvin, N. Sultana, M. Ahmed, R. Sharmin, Z. R. Sharmin. Prescribing Practice of Antibiotics for Outpatients in Bangladesh: Rationality Analysis. Am J Pharmacol. 2018; 1(1):1008.

[29] C. R. Lee, J. H. Lee, L. W. Kang, B. C. Jeong, and S. H. Lee. "Educational effectiveness, target, and content for prudent antibioticuse,"BioMed ResearchInternational, 2015, 13.

[30] S. Leekha, C. L. Terrell, R. S. Edson. General principles of antimicrobial therapy. Mayo Clin Proc. 2011;86:156-167.

[31] S. Mollahaliloglu, A. Alkan, B. Donortas, S. Ozgulcu, A. Akici. Assessment of antibiotic prescribing at different hospitals and primary healthcare facilities. Saudi Pharm J. 2012;21:281-291.

[32] I. A. Nasir, A. Babyo A. U. Emeribe, N. O. Sani. Surveillance for antibiotic resistance in Nigeria: Challenges and possible solution. Trends in Medical Research, 2015, 10(4):106-113.

[33] M. Ntšekhe, N. Hoohlo-Khotle, M. Tlali, D. Tjipura. Antibiotic prescribing pattern at six hospitals in Lesotho. http://apps. who.int/medicinedocs/documents/s21028en/s2102 en.pdf. Published July 2011. Accessed October 7, 2019.

[34] O. O. Oduyebo, A. T. Olayinka, K. C. Iregbu. A. Verspoten, H. Goosens, P. I. NwajiobiPrincewill, O. Jimoh, T. O. Ige, A. I. Aigbe, O. I. Ola-Bello, A. O. Aboderin, F. T. Ogunsola. A point prevalence survey of antimicrobial prescribing in four tertiary hospitals.Annиal Tropical Pathology, 2017, 8:42-46.

[35] O. O. Paul, and A. Abdulmalik. Empirical Antibiotic Prescription Pattern among Patients in a Nigerian Tertiary Hospital, is There Evidence of Irrationality? Journal of Advances in Medicine and Medical Research, 2019, 30(6): 1-11

[36] J. Prah, J. Kizzie-Hayford, E. Walker, A. Ampofo-Asiama. Antibiotic prescription pattern in a Ghanaian primary health care facility. Pan Afr Med J. 2017, 28:214.

[37] D. R. Smith, F. C. K. Dolk, T. Smieszek, J. V. Robotham, K. B. Pouwels. Understanding the gender gap in antibiotic prescribing: a cross-sectional analysis of English primary care. BMJ Open. 2018;8(2):e020203.

[38] S. Streit, P. Frey, S. Singer, U. Bollag, D. N. Meli. Clinical and haematological predictors of antibiotic prescribing for acute cough in adults in Swiss practices-an observational study. BMC Fam Pract. 2015;16(1):15.

[39] A. Sumaila, P. T. Tabong. Rational prescribing of antibiotics in children under 5 years with upper respiratory tract infections in Kintampo Municipal Hospital in Brong Ahafo Region of Ghana. BMC Res Notes (2018) 11:443.

[40] T. S. Summoro, K. D. Gidebo, Z. Z. Kanche, E. W. Woticha. Evaluation of trends of drug-prescribing patterns based on WHO prescribing indicators at outpatient departments of four hospitals in southern Ethiopia. Drug Des DevelTher. 2015, 9:4551-4557

[41] L. W. Umar, A. Isah, S. Musa, B. Umar. Prescribing pattern and antibiotic use for hospitalized children in a Northern Nigerian Teaching Hospital. AnnualAfrical Medicine, 2018, 17(1):26-32.

[42] M. A. Woldu, S. Suleman, N. Workneh, and N. Berhane. Retrospective Study of the Pattern of Antibiotic Use in Hawassa University Referral Hospital Pediatric Ward, Southern Ethiopia.Journal of Applied Pharmaceutical Science, 2013, 3 (02):093-098

[43] F. Worku, D. Tewahido. Retrospective assessment of antibiotics prescribing at public primary healthcare facilities in Addis Ababa, Ethiopia. InterdiscipPerspect Infect Dis. 2018, 43:23769.

[44] World Health Organisation. Drugs and money-prices, affordability and cost containment. Accessed 14 May 2014.

[45] World Health Organization. Antibiotic resistance: multicountry public awareness survey. https://www.who.int/drugresistance/documents/baselinesurveynov201 5/en/. Published November 2015. Accessed October 7, 2019. 